\title{
GADAMER SOBRE EL CONCEPTO ARISTOTÉLICO DE PHRÓNESIS*
}

\author{
Manuel JIMÉNEZ REDONDO \\ Universidad de Valencia
}

RESUMEN. Por más que en Aristóteles no se trate del problema hermenéutico, ni mucho menos de su dimensión histórica, si comparamos el análisis que Aristóteles hace del fenómeno ético (y en particular de la phrónesis) con lo que es el planteamiento de Verdad y método, resulta que, efectivamente, como quiere Gadamer, el análisis que Aristóteles hace de la virtud dianoética de la phrónesis sería una especie de modelo de las cuestiones que en Verdad y método Gadamer plantea como tarea de una hermenéutica filosófica. Esta apelación a la noción aristotélica de phrónesis se convierte además en Verdad método en una crítica de las estructuras formales de la conciencia moderna o en una crítica de la autocomprensión de la conciencia moderna en términos de tales estructuras. Con base en estas ideas de Gadamer, en el artículo se analizan la relación de Gadamer con Hegel, la apelación de Gadamer a Humboldt y a los conceptos de interpretación e historicidad de Heidegger, la noción gadameriana de "rehabilitación del prejuicio", y la crítica de Habermas del "giro ontológico de la hermenéutica».

\section{Algunos temas básicos de la primera parte de Verdad y método}

\section{I.1. Phrónesis}

Al comienzo mismo de Verdad y método, Gadamer apela al concepto aristotélico de phrónesis entendiendo éste como "indicación" de la forma de conocimiento que frente al conocimiento "metódico", es decir, frente al conocimiento

* Ponencia presentada en la reunión que la Sociedad Ibérica de Filosofía Griega celebró en la Facultad de Filosofía de la Universidad de Valencia el 4 de Abril de 2003. 
atenido a lo que en el contexto de la ciencia moderna se llama "método" ${ }^{1}$, tendría acceso a verdades que no nos serían accesibles de otra manera. Hablando de Vico dice: «El saber práctico, la phrónesis, es una forma distinta de saber. Y esto significa de entrada: se dirige a la situación concreta. Tiene, pues, que aprehender las circunstancias en la infinita variedad de éstas. Esto es también lo que Vico subraya en él. Ciertamente, Vico sólo mira a que este saber escapa al concepto racional de saber. Pero en verdad no se trata de un mero ideal de resignación. La contraposición aristotélica se refiere a algo bien distinto que a sólo una contraposición entre el saber a partir de principios generales y el ver de lo concreto. Tampoco se refiere a la capacidad de subsunción de lo particular bajo lo universal que llamamos facultad de juzgar o Urteilslkraft. Antes bien, en esa contraposición opera un motivo positivo, ético, que pasa a formar parte de la doctrina romano-estoica del sensus communis. El aprehender y el dominar éticamente la situación concreta exige una subsunción de lo dado bajo lo universal, es decir, bajo el fin que se persigue, tal que por medio de ello se dé precisamente lo correcto. Presupone ya, pues, una dirección de la voluntad, presupone, por tanto, un ser ético (héxis). De ahí que para Aristóteles la phrónesis sea una virtud espiritual, una virtud dianoética. Él no ve en ella una facultad (dynamis), sino una determinidad del ser ético, el cual no puede ser sin la "totalidad de las virtudes éticas", al igual que esa totalidad tampoco puede ser sin ella. Aun cuando esta virtud, en su ejercicio, introduce una distinción entre lo que puede hacerse y lo que no puede hacerse, no se trata solamente ni de una Klugheit práctica ni de una Findigkeit (habilidad) práctica. Su distinción de lo que es factible y lo que no lo es, implica siempre ya la distinción entre lo que está bien y lo que no lo está y por tanto presupone una actitud ética que con tal distinción no hace sino desarrollarse» ${ }^{2}$. Y añade: "En todas estas variaciones [que experimenta el concepto de phronesis tanto en el Helenismo y en Roma como en el Humanismo moderno] sigue operando la forma del ser ético, de la que Aristóteles se percató y que Aristóteles analizó. El recordarla es importante para una adecuada autocomprensión de las ciencias del espíritu" ${ }^{3}$.

${ }^{1}$ H.-G. GadAMER, Wabrheit und Methode, $1 .^{\text {a }}$ edición 1960, corregida y aumentada, Tubinga, 1986, p. 13.

${ }^{2}$ Ibid., p. 27.

3 Ibid., p. 29. 


\section{I.2. Ciencias del espíritu}

Y de éstas se trata. Recordemos, pues, brevemente el contexto en el que a este respecto se produce en Verdad y método esta apelación al concepto de phrónesis, o esa rememoración de él: «Dilthey puede haber defendido todo cuanto se quiera la autonomía de las ciencias del espíritu, y peleado por ella, pero lo que en la ciencia moderna se llama método, es en todas partes una y la misma cosa, y en las ciencias de la naturaleza no hace sino cobrar una forma particularmente ejemplar. Pero a mi juicio, no existe ningún método propio de las ciencias del espíritu. Ciertamente, uno puede preguntarse con Helmholz qué podría significar aquí método, y si las demás condiciones bajo las que las ciencias del espíritu están o quedan, no son para las ciencias del espíritu mucho más importantes que la lógica inductiva. Helmholz había señalado esto muy bien, cuando para hacer justicia a las ciencias del espíritu había subrayado la función que en ellas desempeña la memoria y la autoridad, y había hablado de tacto psicológico, que habría de sustituir aquí a la inferencia consciente. ¿En qué se basa tal tacto?, ¿cómo se adquiere? Lo científico de las ciencias del espíritu, ¿no radica más en ese tacto que en el método? En todo caso, precisamente porque las ciencias del espíritu motivan esta pregunta $y$, por lo tanto, se resisten a su incardinación en el concepto moderno de ciencia, son y siguen siendo un problema de la filosofía misma. La respuesta que Helmholz y su siglo dieron a esta pregunta no puede hoy bastarnos. Pues siguen a Kant al orientar el concepto de ciencia y de conocimiento por el modelo de las ciencias de la naturaleza, y habían buscado lo distintivo de las ciencias del espíritu en su momento artístico (sentimiento artístico, «inducción artística», interpretados psicológicamente)».

\section{I.3. Ser y tiempo como trasfondo de estas consideraciones sobre las ciencias del espiritu}

Pero el trasfondo de todo lo que acabamos de oír es a su vez la referencia a Ser y tiempo y al Heidegger posterior a Ser y tiempo, si bien, como va a quedar claro a continuación, Gadamer se mantiene también en todo momento a una elegante distancia respecto a él: «La descripción del movimiento que Aristóteles hace en su Física y con la que Aristóteles opera en su Física es algo que no tiene nada que ver con la forma en que llega a aplicarse la Matemática en el siglo XVII. Y eso debe

${ }^{4}$ Ibíd., pp. 13 s. 
tenerse muy en cuenta a la hora de apelar al origen que la ciencia moderna tiene en los griegos. Yo creo que deberían darse por definitivamente pasados los días en que se recurría al método de la ciencia moderna de la naturaleza con el fin de interpretar a Platón por el rasero de Kant y la noción de idea de Platón por el de ley de la naturaleza, o se interpretaba a Demócrito como una especie de prometedor precedente de lo que era el verdadero conocimiento "mecánico" de la naturaleza, es decir, como una especie de precedente de la Mecánica de Galileo y Newton. Si pensamos en que en su básica superación del punto de vista del "entendimiento", Hegel recurría como hilo conductor a la idea de vida, nos daremos cuenta enseguida de la limitación de esa manera nuestra de considerar las cosas. Y a mi entender, Heidegger obtuvo después en Ser y tiempo el punto de vista desde el que hay que entender tanto la diferencia como la conexión entre la ciencia griega y la ciencia moderna. Al analizar el concepto de Vorhandenheit como un modo deficiente de ser, y al reconocerlo como el trasfondo tanto de la Metafísica clásica como de la transformación que ésta experimenta en la Edad Moderna con el concepto moderno de sujeto, Heidegger estaba descubriendo y moviéndose en la pista de la correcta relación entre theoria griega y ciencia moderna. En el horizonte de su interpretación temporal del ser, la metafísica clásica resulta ser en su conjunto una ontologia de lo Vorhanden, y la ciencia moderna, sin barruntarlo siquiera, no es sino la heredera de esa ontología. Pero resulta que en la theoría griega misma se encerraba además otra cosa aparte de eso. La theoría no comprende ni se refiere tanto a lo Vorhanden como a la "cosa misma", a die Sache selbst, la cual tiene todavía la dignidad de lo que Heidegger analizó en su artículo "Das Ding" (La cosa). Que la experiencia de la cosa tiene tan poco que ver con la constatabilidad de lo Vorhanden como con la experiencia de las llamadas ciencias experimentales, es algo que se encargó de subrayar el Heidegger posterior. $Y$ así, tanto la dignidad de la cosa como la referencia del lenguaje a la cosa haremos muy bien nosotros en mantenerlas libres tanto del prejuicio [heideggeriano] contra la ontología de lo Vorhanden [pues ésta contiene más que la referencia sólo a lo Vorbanden] como del concepto de objetividad. Partimos de que en la estructura lingüística de la experiencia humana del mundo, no sólo se calcula o mide lo Vorhanden, sino que viene a la palabra el ente, tal como éste se muestra al hombre en tanto que siendo y en tanto que significando. Y es ahí, y no en el ideal metódico de la construcción racional que domina a la moderna ciencia matemática de la naturaleza en donde puede reconocerse a sí mismo el comprender practicado en las ciencias del espíritu" ${ }^{5}$.

' Ibíd., pp. 459 s. 


\section{I.4. La trascendencia de la obra de arte sobre el conocimiento} metódico. La primera parte de Verdad y método

Y es en la perspectiva tanto de la crítica de tal orientación del concepto de conocimiento por el modelo de las ciencias, como de una liberación del momento de conocimiento del arte, al que apunta Helmholz al tratar de hacerse una idea del modo de conocimiento y valor de conocimiento de las ciencias del espíritu, es así, digo, como, obviamente, hay que entender la primera parte de Verdad y Método, que lleva por título «Liberación de la pregunta por la verdad con base en la experiencia del arte».

Esta "liberación" se efectúa a su vez en dos partes.

La primera parte consiste en un "trascender la dimensión estética", es decir, en una crítica de "la abstracción de la conciencia estética", o lo que es lo mismo: en una explicación de la trascendencia cognitiva de la obra de arte sobre la reducción que el conocimiento metódico introduce y en una correspondiente crítica de la psicologización de lo estético. Gadamer desarrolla esta explicación en tres pasos: mediante una apelación a la tradición humanista, mediante una crítica de lo que entiende que es una «subjetivación de la estética en la Crítica del juicio de Kant", y mediante la «reobtención y replanteamiento de la pregunta por la verdad del artem.

Y en la segunda parte, a partir de dicha reobtención, Gadamer busca o propone una explicación de la trascendencia implicada por la obra de arte en términos de una "ontología de la obra de arte y de su importancia hermenéutica". Para ello Gadamer recurre a uel juego como hilo conductor de la explicación ontológica».

Naturalmente, no puedo detenerme aquí en esta reobtención por Gadamer de la pregunta por la verdad del arte, en la que Gadamer sigue al segundo Heidegger. Pero sí me parece de interés subrayar que, en lo que respecta al recurso al juego como hilo conductor de la explicación ontológica, Wittgenstein habia hecho algo muy similar en sus Investigaciones filosóficas, aunque sin tematizar esa su propia estrategia. Podríamos decir que aquí Gadamer no hace sino tematizar esa estrategia, llevarla a concepto. E incluso puede que Gadamer dependa aqui de Wittgenstein, si bien esto no tiene aquí más importancia. Sí creo que tiene interés indicar que, si se tiene en cuenta esta clase de solapamientos, no puede 
sorprender que discípulos de Gadamer como K.-O. Apel y J. Habermas pudiesen recurrir (precisamente siempre en el contexto de consideraciones sobre Verdad y método) a la tradición de filosofía analítica del lenguaje tal como ésta venía representada básicamente por el segundo Wittgenstein y después por el Quine de "Dos dogmas del empirismo" y por sus discípulos americanos; me refiero principalmente a H. Putnam, D. Davidson y R. Rorty. Pero aquí tengo que dejar esto de lado.

\section{I.5. Con Hegel, pero en definitiva sin Hegel, e incluso claramente contra Hegeh aun- que evidentemente no del todo.}

A pesar de que su lenguaje no carezca de una cierta luminosidad, Verdad y método es en conjunto un texto bien confuso, y en ocasiones no poco superficial, pese a la sensación de profundidad que constantemente le viene prestada por ese nivel de atinada sugerencia en que logra moverse y mantenerse el autor. Nunca se ve del todo cuál es propiamente la "estructura de la prueba", ni siquiera en lo que se refiere a la tesis más básica que el autor introduce desde el principio.

En algún momento de su lectura del libro, puede que el lector incluso llegue a pensar si Verdad y método no es también un cuestionamiento precisamente de esa clara "estructura de la prueba" que el lector sigue constantemente esperando, aunque tampoco ello queda tematizado (y tampoco yo voy a entrar en ello). En todo caso, el lector no puede evitar preguntarse de qué penden o cómo se comprueban la verdad o las verdades que contra "el método" el autor va introduciendo, ya que al lector esas verdades (o la base de esas verdades) le van quedando en una irritante ambigüedad e indeterminación.

Pues como hemos visto, hasta ahora Gadamer ni ha afirmado ni tampoco ha negado la ontología de lo Vorhanden, que, a su juicio, siempre contuvo algo más que el horizonte de la Vorhandenheit. Y asimismo, pese a su insistencia (ya desde el principio del libro) en que la experiencia hermenéutica es una experiencia de finitud, nunca desaparecen del todo del horizonte ni el libro XII de la Metafisica de Aristóteles, ni tampoco su interpretación hegeliana, ni tampoco Hegel. Por otra parte, acabo de poner uno de los capítulos de la primera parte del libro en relación con Wittgenstein, aunque insistiendo en una básica diferencia: en Gadamer se trataría de llevar a concepto lo que en Wittgenstein es estrategia. Y 
cabe preguntarse si en definitiva esto último no podría ser equivalente a decir que en Gadamer se trataría de hacerse concepto incluso de la dimensión de verdad del arte, que allende la idea metódica de la moderna ciencia de la naturaleza como modelo de conocimiento, queda abierta por vía de ese recurso al juego "como hilo conductor de la explicación ontológica", y si esto en definitiva no acaba pareciéndose a Hegel, es decir, a ese Hegel en el que la verdad del arte, muy por encima del pensamiento del «entendimiento», acaba siendo recogida y superada en concepto filosófico.

Y así, cuando se va acercando al final de la primera parte de Verdad y método, al final, pues, de la primera parte de las tres de que consta el libro, el lector se pregunta si ese más allá del pensamiento "metódico", si ese allende el "pensamiento del entendimiento", que en el libro se reclama, junto con el (en definitiva mantenido o nunca del todo argumentativamente negado, o nunca se sabe bien si negado o no negado) horizonte de infinitud de la «metafísica clásica», no será quizá lisa y llanamente Hegel, con quien continuamente Gadamer se viene rozando en su exposición y a quien constantemente en todo caso Gadamer viene aludiendo, ya desde su apelación a las consideraciones de Helmholz sobre la importancia del tacto y de la memoria (Erinnerung) en las ciencias del espíritu. O por lo menos, las consideraciones de Gadamer, sin dejar de sonar al Heidegger de "De la esencia de la obra de arte", empiezan a sonar decididamente a Hegel. No olvidemos que ese "pensamiento de la vida" de Hegel que desde el principio del libro viene atrayendo tanto a Gadamer como superación de la perspectiva del Verstand o entendimiento y desde el que Gadamer apela a la noción de phrónesis, se le convierte a Hegel en Erinnerung absoluta. Y en tal Erinnerung (es decir, en tal Rekonstruktion e Integration, que no Destruktion), y en todo caso, en tal hacer memoria, se cifra también para Gadamer la posibilidad de recuperación de las distintas dimensiones de la "cosa misma" frente a la reducción "metódica» que esa forma ejemplar de conocimiento representada por la ciencia matemática de la naturaleza impone.

Pero no, esa Erinnerung o memoria que busca Gadamer, no puede interpretarse en el sentido del "pensamiento de la vida" como Erinnerung absoluta, como reconstrucción que pudiera darse por entero alcance a sí misma, en el sentido de Hegel. De forma no del todo convincente (pues la perspectiva de la metafísica clásica siempre queda pese a todo mantenida), ello queda tajantemente negado, y al lector no puede menos de antojársele que tal negación sucede un tanto dogmáticamente, si se tiene en cuenta esa permanente referencia de Gadamer a Hegel, 
mediante la que en Verdad y método queda siempre relativizada la presencia de Heidegger. Al final de esa primera parte leemos: "[Con la noción de Erinnerung] Hegel apunta por encima de toda la dimensión en la que para Schleiermacher se planteaba el problema del entender o Verstehen. Hegel lo eleva y pone sobre la base sobre la que funda la filosofía como forma suprema del Espíritu Absoluto. En el saber absoluto que representa la filosofía se consuma aquella autoconciencia del espíritu, que, como dice el propio texto de Hegel, comprende también dentro de sí "de una forma superior" la verdad del arte. Y así para Hegel es la filosofía, es decir, el darse el espíritu histórica y conceptualmente alcance a sí mismo, la que representa y significa dominar la tarea hermenéutica y acabarla. Ese darse alcance el espíritu representa la contraposición extrema al auto-olvido de la conciencia histórica [al que Gadamer viene oponiendo la noción de Erinnerung de Hegel]. A ese darse alcance del espíritu en la Erinnerung el comportamiento historicista del representarse todo [del convertir todo en objeto de representación] se le convierte en un pensante comportamiento respecto al pasado [es decir, la Erinnerung hegeliana supera la conciencia historicista en la dirección de un actual recuperarse del olvido metódico de la cosa misma]. Hegel expresa así una decisiva verdad en cuanto que la esencia del espíritu histórico no radica en la restitución del pasado, sino en la pensante mediación con la vida actual. Y Hegel tiene toda la razón cuando no entiende tal pensante mediación como una relación externa y a posteriori, sino que la pone en el mismo nivel que la verdad del arte. Por tanto, Hegel queda muy por encima de la idea de hermenéutica de Schleiermacher. También a nosotros la cuestión de la verdad del arte nos ha forzado tanto a una crítica de la conciencia estética como de la conciencia histórica, en cuanto nos preguntamos por la verdad que se manifiesta en el arte y en la historia». ${ }^{6}$ Y sin embargo, este acuerdo con Hegel, esta aceptación básica de lo más fundamental de Hegel, se produce en el contexto de la taxativa afirmación de que la idea de saber absoluto (es decir, de que la idea absolutizada de Erinnerung, de que la idea de absolute Erinnerung) es la negación lisa y llana de la conciencia y de la experiencia hermenéuticas. Sin embargo, insisto en que, a mi juicio, es esta continua referencia a Hegel (Hegel es uno de los autores más citados en Verdady método) la que permite a Gadamer mantener su elegante distancia respecto a Heidegger, del que, sin embargo, como vamos a ver, depende en lo esencial, o al menos eso se dice (respecto a lo cual yo quiero mantener también mi distancia).

${ }^{6}$ Ibíd., 174. 


\section{La segunda y tercera parte de Verdad y método. EI recurso a Heidegger. "Gadamer urbaniza la provincia heideggeriana" (Habermas)}

\section{II.1. El Verstehen como "método" de las ciencias del espiritu}

La segunda parte de Verdad y método lleva por título "Ampliación o extensión de la cuestión de la verdad a la comprensión (Verstehen) en las ciencias del espíritu». Ni que decir tiene que se trata de la noción de verdad obtenida del replanteamiento de la cuestión de la verdad del arte, de una noción de verdad, por tanto, que excede la verdad obtenible en la perspectiva de la comprensión metódica de la ciencia moderna.

Y esa segunda parte del libro Verdad y método, tiene a su vez dos partes. Una primera parte en la que se desarrolla una prolija discusión de la problemática de las ciencias del espíritu ya enunciada al comienzo del libro. En esta primera parte se termina apelando a Ser y tiempo de Heidegger a través (¿cómo no?) de la discusión entre Dilthey y el Conde de Yorck en la correspondencia entre ambos. Y una segunda parte en la que se exponen «los rasgos básicos de una teoría de la experiencia hermenéutica». En esta secunda secundae, es decir, en esta segunda parte de la segunda parte del libro, Gadamer (que, a mi juicio, es claro que conoce también el texto de Heidegger de 1924 Ontologia: hermenéutica de la facticidad, al que, si no me equivoco, alude expresamente varias veces) recurre, como es bien sabido, a Ser y tiempo.

Ya en las primeras líneas de la segunda parte del libro Gadamer apela (elegantemente, pero diríase que por de pronto incomprometidamente) al carácter de "ontología fundamental» de Ser y tiempo. De forma sólo sugerente, Gadamer empieza dando así alcance a lo que en «la ontología de la obra de arte y su interpretación hermenéutica” de la primera parte había quedado (repito) sólo sugerido (y que si acaso se había hecho valer quizá desde Hegel y en todo caso finalmente contra Hegel), es decir, a la idea de un conocimiento que quedase por encima de la idea metódica de la ciencia moderna. Lo sugerido allí a propósito de la obra de arte, Gadamer lo analiza concienzudamente aquí (aunque sobre bases sólo sugeridas) a propósito de la cuestión de la comprensión, del Verstehen, como «método» (sea dicho aquí con perdón) de las ciencias del espíritu. Pues esta es la cuestión de la que en definitiva se trata en el libro: de la especificidad de las ciencias del espíritu como problema filosófico. 
En virtud del carácter de ese su "método» (el Verstehen), las ciencias del espíritu exceden con mucho la noción de "método» implicada por las ciencias experimentales modernas y quedan en sitio distinto que éstas. Igualmente, quedan en un sitio distinto el tipo de experiencia y la noción de experiencia que las ciencias del espíritu implican.

Frente a ella, la experiencia de las ciencias experimentales representa un tipo peculiarmente reducido de experiencia, el cual tiene desde luego su función precisamente en el "contexto de sentido» de un "mundo" (o en que consiste el mundo), que las ciencias del espíritu tratan de entender. "Mundo», naturalmente, se entiende aquí en el sentido de esa estructura de la existencia humana que es el ser-en-el-mundo.

En este intento, las ciencias del espíritu no son sino la forma reflexiva (Interpretation) de la Auslegung o interpretación que el estar-en-el-mundo, o ser-en-el mundo en que consiste la existencia implica ya de por sí. Conforme al análisis que de la existencia hace Heidegger en Ser y tiempo, el ser-en-el-mundo tiene dos momentos, el encontrarse (o facticidad) y el entender (o Verstehen). Pues bien, la interpretación (Auslegung) «es el desenvolvimieto del entender. En ella el entender hace entendientemente suyo lo entendido. En la interpretación el entender no se convierte en otra cosa, sino en él mismo. La interpretación se basa existencialmente en el entender, y no es que aquél surja por éstan" ${ }^{7}$. Las ciencias del espíritu son, como digo, la forma reflexiva (Interpretation) de esa interpretación (Auslegung).

\section{II.2. Heidegger y Humboldt}

Pero es en la tercera y última parte de Verdad y método donde se consuma y se aclara el sentido de la interpretación "ontológica" que en la segunda parte viene sólo sugerida sin que se vea del todo en qué sentido se habla de "ontología". Y esa consumación se hace de nuevo a su vez por vía de sugerencia.

Por un lado, la interpretación no es sino el modo como la existencia es lo que es, a saber: ser-en-el-mundo. Y por otro lado, Gadamer pone el lenguaje en el

${ }^{7}$ M. HeIDegger, Sein und Zeit, Tubinga, 1927, p. 148. 
centro mismo de la existencia, es decir, introduce el lenguaje en el centro mismo del tener la existencia mundo o del ser la existencia ser-en-el-mundo, apelando para ello a la idea de Humboldt de que el lenguaje empieza siendo el modo como a la existencia le viene abierto algo así como mundo. El modo como quedan aunados el motivo heideggeriano de la Auslegung y el motivo humboldtiano de la "apertura lingüística de mundo", no deja de tener un cierto aspecto de elegante ensalada. Pero en Gadamer casi todo sucede, como digo, por esta vía de elegante sugerencia y sólida erudición, en la que nunca parece sentirse la necesidad de atar definitivamente los cabos. A mí esta forma de proceder (precisamente en este punto) no me convence; pero se diría que en definitiva a Gadamer no le importa si Humboldt concuerda del todo con Heidegger o no, e incluso que para Gadamer no es lo decisivo si él está aceptando del todo a Humboldt o no. Más bien se trata de que en Verdad y método Humboldt está tan magnífica y humanísticamente bien contado (y lo digo de verdad y sin la menor ironía), que en definitiva no hay más que decir, habida cuenta de la deslumbrante autoridad que ese Humboldt así expuesto ejerce, no dejando desde luego de ser él muy distinto de nosotros, que así quedamos también libres frente a él. Pero sea como fuere, lo que ese Humboldt dice no es lo que dice Heidegger en Ser y tiempo (y yo estaría por decir que ello difícilmente se le puede estar escapando a Gadamer, quien, siguiendo a Heidegger se pone así a distancia de Heidegger, también por este lado. Verdad y método no es, pues, Hegel, ni es Heidegger, ni es Humboldt, ni tiene por qué serlos; pero el problema es que no llega a saberse bien qué es).

\section{II.3. La ontologización del Verstehen}

En todo caso en ello (en tal elegante ensalada) consiste esta tercera y última parte de la obra, que lleva por título «Giro ontológico de la hermenéutica siguiendo el lenguaje como hilo conductor" y que consta de tres secciones que llevan respectivamente por título: «El lenguaje como medio de la experiencia hermenéutica», «La acuñación del concepto de lenguaje en la historia del pensamiento occidental" $\mathrm{y}$ "El lenguaje como horizonte de una ontología hermenéutica». Esta ontología no puede menos de comportar una "pretensión de universalidad de la hermenéutica» así ontologizada. Y es así como termina el libro.

El sentido de esa "ontología hermenéutica" $y$, por ende, el sentido en que Humboldt y Heidegger quedan adunados a esa hermenéutica ontologizada, y por tanto universalizada, se puede resumir del siguiente modo (y creo que esto 
constituye la tesis más básica del libro): «Por la vía de nuestro análisis del fenómeno hermenéutico nos hemos topado con la función universal de la lingüisticidad. $\mathrm{Y}$ en cuanto se nos pone de manifiesto el fenómeno hermenéutico en esa su lingüisticidad, no ha podido menos de cobrar un significado universal. Entender e interpretar están subordinados de forma específica a la tradición lingüística. Pero trascienden a la vez esa subordinación, no sólo en cuanto que todas las creaciones culturales de la humanidad, también las no lingüísticas, exigen ser entendidas de esa manera, sino de forma aún mucho más básica y fundamental en el sentido de que todo lo comprensible en general tiene que ser accesible al entender y a la interpretación. Del entender (Verstehen) y de la interpretación puede decirse exactamente lo mismo que del lenguaje. Ambos han de entenderse no sólo como un factum que se puede investigar empíricamente. Ambos no son meramente objeto, sino que abrazan todo lo que en cada caso puede convertirse en objeton ${ }^{8}$. Abrazan todo lo que puede convertirse en objeto y son la materia de la que está hecho todo lo que pueda considerarse sujeto. La ontología hermenéutica, que en estos términos se entiende genuinamente como "ontología (el ser no es sino en la comprensión del ser), queda allende la filosofía moderna del sujeto, y también de la ontología tradicional de la Vorhandenheit de la que la moderna distinción básica de sujeto-objeto es heredera, superando si acaso al alza esa ontología tradicional en la dirección de "la cosa misma» en el sentido dicho más arriba, sugerido desde luego por Hegel. La tesis de esta tercera parte de Verdad y método, y por tanto la conclusión final del libro, pese a venir fundada sólo por vía de sugerencia, no deja de ser radical (y creo que ajena a Ser y tiempo y ajena en general a los protagonistas del retorno a la tradición ontológica a partir de las "consecuencias de la Fenomenología»).

\section{Interpretación e historicidad. La universalidad de la razón, o la idea de «fusión de horizontes».}

Naturalmente, no puedo entrar aquí a exponer con más detalle esta tercera parte del libro de Gadamer.

Voy a retornar más bien a la secunda secundae, es decir, a la segunda mitad de la segunda parte de Verdad y método, es decir, a «los rasgos básicos de una teo-

${ }^{8}$ GADAMER, Wabrheit und Methode, loc. cit., p. 408. 
ría de la experiencia hermenéutica", y desde ahí me referiré también a algunos temas de la parte tercera.

En esa secunda secundae se contiene básicamente la teoría de la Auslegung y de la Interpretation (como forma teórica de la Auslegung) que Heidegger desarrolla en Ser y tiempo, aparte de un resumen muy sucinto (pero que ha resultado extraordinariamente influyente) de las consideraciones de Heidegger sobre la historicidad de la existencia en el capítulo quinto de la segunda parte de Ser y tiempo.

Después de lo dicho, nada puede tener de extraño que lo que ya en el concepto de historicidad de Heidegger es tradición o entrega que la existencia se hace de sí misma a sí misma yéndose ella a recoger (como futuro de sí) a las posibilidades en que se encuentra consistiendo (es decir, la existencia hace-presente o es ella presente en ese estar viniendo a las posibilidades de sí con las que se encuentra ahí), nada tiene de extraño, digo, que ello se convierta en Gadamer en el Geschehen (que no ousia, ni substantia, ni sujeto) de una tradición lingüísticamente articulada y humanísticamente entendida, en la que (y como la que) la existencia se encuentra siendo, entendiendo su mundo y entendiéndose en él. De nuevo tenemos un Heidegger elegantemente «urbanizado", o mejor tenemos la trama de los conceptos más básicos de la ontología fundamental de Heidegger, dados por obvios, pero, eso sí, dados «incomprometidamente» por obvios. Esto último es al menos la impresión que las explicaciones de Gadamer me producen.

$Y$ es en el centro de este Heidegger elegantemente, y en todo caso humanísticamente, urbanizado, donde Gadamer pone después la idea de Humboldt de que hablar es antes que nada "un entenderse con alguien sobre algo". De modo que lo que queda en el centro del Geschehen (acontecer) que es la tradición es una "lógica de las razones" a través de la cuales trato de entenderme con el otro sobre «la cosa", die Sache, das Ding. En ello ese otro, que es fuente de razones, y por tanto nunca reductible a objeto, puede hacérseme presente en su comunidad de horizonte interpretativo conmigo o también en su completa extrañeza, es decir, como no participando de mi horizonte de comprensión y forzándome a una ampliación de mi horizonte de interpretación y a una fusión con el suyo.

El que la posibilidad de ello se repita una y otra vez, el que siempre sea posible una fusión de horizontes, es decir, la mediación de lo particular por algo que 
lo excede, eso, digo, representa algo así como la experiencia de la universalidad de la razón, o quizá mejor: del no particularismo de la razón, y en todo caso la experiencia más básica de las ciencias del espíritu.

Como es de sobra sabido, de estas ideas ha hecho uso y abuso J. Habermas. Pero no sólo él, naturalmente.

Y como es también sabido, esta secunda secundae (esta segunda parte de la segunda parte de las tres que componen Verdad y método) consta de tres apartados con sus correspondientes subapartados.

Los tres apartados llevan respectivamente por título «Elevación de la historicidad del entender a principio hermenéutico", «Recuperación del problema hermenéutico básico" y "Análisis de la conciencia articulada en términos de Wirkungsgeschichte o de historia efectual».

En el primero de los apartados, el más importante, que contiene todo lo esencial, y que tiene a su vez por subapartados «El círculo hermenéutico", «Los prejuicios como condiciones del entender», «El significado hermenéutico de la distancia temporal» $\mathrm{y}$ «El principio de la Wirkungsgeschichte», nos encontramos con un Ser y tiempo sorprendentemente reducido al $\$ 32$ (Verstehen und Auslegung) y a algunos motivos del capítulo quinto de la segunda parte, que, como digo, versa sobre la historicidad.

[Y yo creo que conviene añadir aquí, aunque sea entre corchetes, que es precisamente en este primer apartado de la secunda secundae, al percatarse uno de la drástica (y admirable) reducción que Gadamer lleva a cabo de la temática de Ser y tiempo hasta convertirla en esa ontología hermenéutica que gira en torno a los conceptos de lingüisticidad, entender, interpretación y tradición, es precisamente entonces, digo, cuando a uno se le hace patente lo sofocante y atosigante del reducido horizonte de esa "ontología de la lingüisticidad" en la que ha consistido buena parte del pensamiento de posguerra (en Centroeuropa desde luego por la influencia conjunta de Wittgenstein y de Gadamer). Esa ontología acaba viéndose en definitiva atrapada en un perpetuo oscilar entre un universalismo infundado o nunca bien fundado y un relativismo imposible, y lo que es peor, se ve sistemáticamente empujada a correr el riesgo de no tener más tema que ése. Cuan- 
do uno lee, por ejemplo, la interpretación que hace Zubiri' de esos mismos temas precisamente desde el mismo capítulo quinto de la segunda parte de Ser y tiempo, es decir, desde el capítulo sobre la historicidad de la existencia, que también a Gadamer se le convierte en clave, uno tiene la sensación de recibir algo así como una bocanada de aire fresco. Cuando examina bien a qué se debe esa sensación, uno se da cuenta de que esa sensación se debe simplemente a que en la interpretación de Zubiri una abierta ontología de la inteligencia humana (con sus conceptos centrales de "realidad» $\mathrm{y}$ «ser», previos en todo caso a los de lingüisticidad y de los que el logos deriva) ha sustituido a la ontología de la lingüisticidad en la que Gadamer deja atrapada la temática heideggeriana. Pero olvídense de lo que acabo de decir, que no es propiamente nuestro tema].

\section{En Verdad y método sólo se ha hablando en el fondo de la phrónesis aristotélica}

Pues bien, es en el apartado segundo de esta secunda secundae, el titulado «La recuperación del problema hermenéutica básico», donde bajo el subtítulo de «La actualidad hermenéutica de Aristóteles" nos encontramos con una densa y radical apelación al concepto aristotélico de phrónesis, el cual queda, por tanto, en el centro mismo de Verdad y método.

Y a mí es precisamente esta actualidad hermenéutica de Aristóteles, que a Gadamer se le sigue de su peculiar recepción y reinterpretación del concepto de Auslegung, unido al concepto de historicidad de Ser y tiempo, es esta actualidad, digo, la que me parece del todo cuestionable y efímera frente a aquel concepto aristotélico de phrónesis del que precisamente Heidegger en su curso de 1924 Grundbegriffe der aristotelischen Philosophie obtenía el concepto y explicación de la Auslegung, que aparecen en Ser y tiempo, y que Gadamer toma.

$\mathrm{Y}$ digo esto porque me parece que esa "actualidad" que Gadamer atribuye a Aristóteles, y tal como Gadamer se la atribuye (es decir, ligada a la ontología de la lingüisticidad), si no ha generado, sí que ha dado muy básico pábulo y nutrimento (por lo menos en la filosofía centroeuropea, pero no sólo en ella) a dos

9 Cfr. X. ZUBIRI, "La dimensión histórica del ser humano», en Realitas I 1972-1973, Madrid, 1973, pp. 11-69. 
polémicas en filosofía práctica desde principios de los años setenta en adelante, que, vistas desde las interpretaciones del propio Heidegger, me parece que son un sinsentido.

Me refiero a las polémicas entre kantismo y aristotelismo o neoaristotelismo, por un lado, y a la polémica entre particularismo y universalismo, por otro, que, aunque son distintas, en importantes trechos se solapan entre sí (naturalmente, sólo muy limitadamente podré entrar en estos temas, lo haré al final).

Como es bien sabido, Gadamer empieza introduciendo su idea de dicha actualidad en términos que el propio Gadamer sabía muy bien que tenían que resultar extremadamente polémicos, pues asimilan toda hermenéutica al tipo de hermenéutica autoritativa que representan la hermenéutica teológica y la hermenéutica jurídica.

Dice: "Si todo esto es así [si toda interpretación es siempre cognitiva, normativa y reproductiva], se plantea la tarea de determinar nuevamente la hermenéutica de las ciencias del espíritu, precisamente a partir de la hermenéutica jurídica y de la hermenéutica teológica [que Gadamer ha venido considerando en las páginas anteriores, las cuales parten de textos autoritativos, el haberse correcto respecto a los cuales es un haberse con phrónesis en la aplicación de lo universal que aquellos textos contienen a este caso concreto o esta situación concreta]. La distinción entre una función cognitiva y una función normativa separa por completo (y las desgarra) cosas que se copertenecen. Pues bien, el sentido de la ley, que se prueba en la aplicación normativa, no es nada que en principio sea distinto del sentido de la cosa que se hace valer en el entender un texto. Es una extravagancia querer fundar la posibilidad de entender los textos en una congenialidad que habría de unir al autor de ellos y a su intérprete. [...] La maravilla del entender radica en que no necesita de tal congenialidad para conocer lo verdaderamente significativo y lo dotado originalmente de sentido en la tradición, sino que podemos abrirnos a la pretensión de superioridad del texto (o a la superior pretensión del texto) y corresponder comprensivamente (entendientemente) al significado en que nos habla. La hermenéutica en el ámbito de la filosofía y de las ciencias históricas del espíritu no es "saber de dominio o de dominación", es decir, una apropiación como toma de posesión, sino que se subordina a la pretensión dominante del texto (o a la pretensión de dominación del texto). El verdadero modelo de ello lo constituyen la hermenéutica jurídica y la hermenéuti- 
ca teológica. Ser interpretación de la voluntad del legislador, ser interpretación de la promesa divina, éstas son, manifiestamente, no formas de dominación, sino formas de servicio. Al servicio (o estando al servicio) de aquello que ha de valer, es decir, al servicio de lo que ha de considerarse válido [es decir, al servicio de aquello válido en lo que de antemano el entender se mueve y que por tanto integra la "estructura de prejuicios del entender"], esas interpretaciones son interpretaciones que incluyen aplicación. Y mi tesis es que, igualmente, también la hermenéutica histórica ha de efectuar un trabajo de aplicación en este sentido, porque también ella está al servicio de la validez del sentido al colmar expresa y conscientemente la distancia temporal que separa al intérprete de los textos y supera el extrañamiento de sentido (es decir, el no entenderse ya) que los textos han experimentado" ${ }^{10}$.

Pues bien, si se miran bien las cosas, para Gadamer esto no es sino el concepto aristotélico de phrónesis. "Con lo cual la ética aristotélica cobra para nosotros una importancia especial, que ya hemos tocado en nuestras consideraciones introductorias a la teoría de las ciencias del espíritu. Ciertamente, en Aristóteles no se trata del problema hermenéutico, ni mucho menos de su dimensión histórica, sino de la correcta mensura del papel que la razón ha de desempeñar en la acción ética. Pero precisamente eso es lo que nos interesa a nosotros aquí, lo que nos interesa es precisamente que se trata de una razón y un saber que no están disociados de un ser que ha devenido tal [el ser histórico], sino que se determinan a partir de éste y que son determinantes para éste»" "También el problema hermenéutico se deslinda de un supuesto saber puro, que estuviese disociado de su propio ser» ${ }^{12}$.

Pero no se trata de acumular citas. Después de un análisis, no sé si espléndido, pero que no carece de luminosidad y brillantez, de la noción aristotélica de phrónesis, Gadamer llega a la conclusión de que en Verdad y método no se ha tratado de otra cosa, sino de lo mismo: «En resumen, si ponemos en relación la descripción que Aristóteles hace del fenómeno ético y en particular de la phrónesis, es decir, de la virtud del saber ético, si ponemos en relación esa descripción, digo, con lo que es nuestro planteamiento, resulta que efectivamente el análisis aris-

${ }^{10}$ GADAMER, Wabrheit und Methode, ed. cit., p. 316.

11 Ibíd., p. 318.

${ }^{12}$ Ibíd., p. 319. 
totélico es una especie de modelo de los problemas planteados en lo que hemos descrito como tarea hermenéutica» ${ }^{13}$.

\section{Una dudosa actualidad de Aristóteles.- Crítica de la abstracción del derecho natural.- Habermas contra «la pretensión de universalidad de la hermenéutica"}

Pero resulta que casi en los mismos pasajes, esta apelación al concepto aristotélico de phrónesis como coincidiendo con (o como conteniendo básicamente) las cuestiones de las que se trata o se ha tratado en Verdad y método, queda interpretada simultáneamente por Gadamer, si no como una crítica y recusación de nada menos que de la idea de "derecho natural racional moderno», sí como una seria relativización y cuestionamiento de esa idea. Dice: «Pese a lo claro que resulta el texto de Aristóteles, las posteriores teorías del derecho natural han apelado a este pasaje de Aristóteles [en que éste habla de algo así como derecho natural] como si Aristóteles hubiese comparado la inmutabilidad del derecho con la inmutabilidad de las leyes naturales. Nada de eso. La idea de derecho natural sólo tiene en Aristóteles una función crítica. No se debe hacer de ella un uso dogmático, es decir, no se puede dotar a ningún contenido jurídico de la dignidad e invulnerabilidad de algo así como un derecho natural [naturalmente tampoco al derecho básico kantiano de libertad como único derecho innato que asiste al hombre en virtud de su humanidad]. La idea de un derecho natural es para Aristóteles imprescindible en vistas de las deficiencias de todas las leyes vigentes, y se vuelve particularmente actual cuando se trata de consideraciones de equidad, que son las que verdaderamente dan con el derecho. Pero su función es crítica en la medida de que sólo allí donde aparece una discrepancia interpretativa entre derecho y derecho ( $y$ en la perspectiva de ello), es legítima la apelación al derecho natural, ${ }^{14}$.

Esto era demasiado para algún joven discípulo o colega de Gadamer, y desde luego no sólo para él. "La pretensión de universalidad de la hermenéutica" $(1970)^{15}$ de J. Habermas contiene una rotunda y encendida crítica conjunta de dos cosas. Primero, de lo que Habermas considera una rehabilitación del pre-

13 Ibíd., p. 329.

la Ibíd., p. 325.

15 Cfr. J. HABERMAS, Zur Logik der Sozialwissenschaften, Fráncfort, 1982, pp. 331 ss. 
juicio como tal por la vía de esa pretensión de superioridad que se concede en definitiva a lo que en cada caso es la contingente "estructura de prejuicio» o estructura de autoridad del entender; y segundo, de la relativización "neoaristotélica" que junto con ello casi necesariamente efectúa Gadamer de algo así como las estructuras formales de la conciencia moderna, y en concreto de esa forma que obligatoriamente ha de tener todo lo que pueda considerarse ley, que representa el «imperativo categórico» de Kant. Y como es bien sabido, para el Kant de la "teoría del derecho" de la Metafisica de las costumbres, implicaciones del carácter universal y formal de ese abstracto "imperativo de la razón" son tanto el "principio del derecho privado» como el "principio del derecho público» (es decir, el "principio de la mayor libertad formal posible conforme a leyes generales", y el "principio democrático" que establece de dónde habrían de provenir esas leyes); esos dos principios son los supuestos más básicos de lo que podemos llamar ilustración política o sociopolítica moderna.

Ambas cosas, es decir, tanto la rehabilitación del prejuicio como tal, como la radical relativización de esa peculiar formalidad o formalismo o abstracción de las estructuras de la conciencia moderna (al menos tal como éstas quedan descritas por Kant), las atribuye Habermas a la ontologización de la hermenéutica que Gadamer lleva adelante ya desde la primera parte de Verdad y método. Es decir, ambas cosas, que Habermas considera sumamente rechazables, él las achaca conjuntamente a la apelación de Gadamer a "De la esencia de la obra de arte" de Heidegger para introducir la idea de una verdad envolvente que excede a la obtenible conforme a la idea de método de la ciencia moderna; a su obvia interpretación de ello conforme a la idea de Ser y tiempo de una ontología que habría de superar al alza a la tradición ontológica, a la extensión de ello a "metodología» de las ciencias del espíritu, y a esa tesis (totalmente dependiente de la interpretación heideggeriana) que es la de la universalidad de una hermenéutica así ontologizada. Es en esa ontología hermenéutica con pretensiones de universalidad y ultimidad, donde para Habermas las categorías de la ontología fundamental de Heidegger y los conceptos más básicos del Heidegger posterior quedan reinterpretados en términos de una ontologización de la tradición (y del prejuicio) y de una decidida deslegitimación de las estructuras de la conciencia moderna. Y ello por más que dicha deslegitimación quede atemperada por una culta, elegante y urbana apelación a la tradición humanista, que tampoco es sin más la tradición que sirvió de vehículo a las estructuras de la conciencia moderna. 
Y Habermas propone olvidarse por entero de la maldita idea de tal ontologización, y en todo caso considera insuficiente esta «urbanización de la provincia heideggeriana", que en definitiva deja humanísticamente intacta la antiilustrada fatalidad de esa "provincia" y la asimismo antiilustrada o contrailustrada fascinación que esa agreste "provincia" sigue ejerciendo. Pues pone contrailustradamente a su favor los puntos en los que la Ilustración necesita ciertamente ilustrarse sobre sí misma, pero no, desde luego, hacer dejación de sí misma. La hermenéutica filosófica de Gadamer representaría una forma amable y urbanizada del conservadurismo alemán, que, precisamente por eso, mantendría (o podría contribuir a mantener), sin embargo, intacta la veta más contrailustrada de éste. A lo cual no serían en definitiva óbice todas las apelaciones que se quieran a la universalidad de la razón, articulada en términos de la noción de "fusión de horizontes».

\section{La rehabilitación de los prejuicios como condiciones del diálogo que somos. Humboldt y Gadamer}

La idea de "el diálogo que somos» ${ }^{16}$ se funde en Gadamer con una ontologización del concepto aristotélico de phrónesis. Esa interpretación actualizadora de Aristóteles, que a Habermas le resulta tan rechazable, tendría, pues, que ver con los términos en que Gadamer hace suya (muy a su manera) esa superación al alza que Heidegger busca realizar de la propia tradición ontológica. Esa superación se produce en forma de una crítica de los conceptos básicos de la filosofía del sujeto (de Descartes a Husserl, pasando por Hegel y quizá también por Kant), que Heidegger considera heredera de aquella tradición ontológica.

Esa misma idea de "el diálogo que somos" que Habermas toma desde el principio de Gadamer y que en todo caso tanto en Gadamer como en Habermas proviene también de Humboldt ${ }^{17}$, Habermas busca desarrollarla, en cam-

\footnotetext{
16 Wabrheit und Methode, p. 383.

17 Para entender bien las relaciones entre Gadamer y Habermas debe tenerse presente que La Lógica de las ciencias sociales de Habermas no es sino la recensión de Verdad y método que el propio Gadamer pidió a su joven colega Habermas, y que a éste se le hizo interminable. Tanto en La lógica de las ciencias sociales, como en Conocimiento e Interés, como en "La pretensión de universalidad de la hermenéutica" lo que busca Habermas es (por la vía de una crítica de la ontologización de la hermenéutica filosófica) reducir su pretensión de universalidad y poner esa hermenéutica filosófica en su sitio.
} 
bio, en forma de una filosofía trascendental, renovada en términos de filosofía del lenguaje. En ella relucen más aún, si cabe, que en la "filosofia del sujeto" de Kant la abstracción, el formalismo y la universalidad de las estructuras de la conciencia moderna, de la razón ilustrada. En todo caso, igual que Gadamer, es desde «el diálogo que somos» desde donde Habermas trata de «acercarse a la oscuridad del lenguaje” ${ }^{18}$ [A Habermas le gustó muchísimo desde el principio esa idea de «el diálogo que somos», que enseguida vio metódicamente sustanciada en G. H. Mead ${ }^{19}$, porque, eso sí, contra Gadamer se produce en Habermas una obsesiva afirmación del carácter "metódico" y científico del saber, ya se trate de saberes que respondan a un interés cognoscitivo técnico, de saberes que respondan a un interés cognoscitivo práctico, de saberes que respondan a un interés cognoscitivo emancipatorio, o de saberes que consistan en una sistemática reconstrucción de competencias universales de la especie. Pero no puedo entrar en esto].

Aunque no apele a ellos directamente, Gadamer rememora (a su manera) en Verdad y método algunos conocidos conceptos de Humboldt, a los que también Habermas ha recurrido masivamente a fin de «lingüistizar» motivos provenientes de la filosofía del sujeto y de los clásicos de la teoría sociológica. Humboldt distingue entre el lenguaje como érgon y el lenguaje como enérgeia $a^{20}$. El lenguaje como érgon es el resultado del ejercicio del hablar, el producto linguístico. $Y$ en definitiva, como hemos visto, no solamente los productos estrictamente lingüísticos, sino todo érgon humano habrá de caer en algún sentido bajo la jurisdicción de ese concepto del lenguaje como érgon, pues toda obra humana vendrá "dicha" por una u otra vía, o en todo caso vendrá "lingüísticamente mediada", o no habrá sido posible sin lenguaje.

El lenguaje como enérgeia, es decir, el ejercicio del estarse entendiendo (o estar uno tratando de entenderse) con alguien sobre algo, del que el lenguaje como érgon es resultado, viene a la vez posibilitado por la existencia del lenguaje, y por tanto por el lenguaje como érgon. Es decir, el hablar, del que el lenguaje como érgon ha de considerarse el producto, viene a su vez circularmente posibilitado por ese mismo lenguaje como érgon, tanto por el lenguaje como érgon

18 Wabrheit und Methode, p. 383.

19 Cfr. G. H. MEAD, Mind, self and society, Chicago, 1934.

20 Wabrheit und Methode, p. 445. 
en sentido estricto como en sentido amplio; viene posibilitado, pues, por todo aquello sobre lo que el hablante pisa. (Es así como, por utilizar una conocida expresión de Heidegger, la existencia humana es geworfener Entwurf, esto es, iectata proiectio, es decir, un entender y entenderse sobre la base de lo sido, un haber de proyectarse que se encuentra echado ahí).

Y esto coincide, o en todo caso se solapa ampliamente, con lo que para Gadamer es la "estructura de prejuicios" del entender, que es una noción que Gadamer directamente deriva de lo que Heidegger en Ser y tiempo llamaba la Vor-struktur de la interpretación (la prae-structura, o mejor estructura-prae de la intepretación). Es decir, sólo es posible entender, y sólo es posible entenderse, sobre la base de aquello en lo que ya se está o que ya se tiene (prae-habere), desde la visión que de antemano se tiene de aquello en lo que ya se está o que ya se tiene (prae-visio), y con los conceptos en que de antemano se articula (praeconceptio) esa visión que de antemano se tiene de aquello en lo que se está o aquello que de antemano se tiene. De modo, digo, que el lenguaje como enérgeia, sin el cual no es concebible el lenguaje como érgon, no es a su vez concebible sin aquel érgon en el que y desde el que al hablante le queda abierto y le viene abierto el mundo, o la cosa misma, que en el ejercicio del habla se retoma.

Y es así como el entenderse, es decir, es así como el diálogo que somos, en esta su circularidad, no es sino el pasar (el acontecer, el Geschehen) de una tradición, que cuando lo es de verdad no es sino un producirse (es decir, un acabar viniendo como acreditándose en su verdad) aquello que de verdad ya siempre era (es decir, la cosa misma o asunto de cuya verdad se trataba) y como cuya verdad se revela el entender y el entenderse genuinos. El genuino entender y entenderse, tal como lo interpreta Gadamer, precisamente por tener esencialmente que ver con la cosa misma de la que en el entenderse se trata, tiene, pues, mucho que ver con algo así como ejemplaridad y autoridad, es decir, tiene que ver con el entender tal como el phronimos entiende, y con el actuar tal como el phrónimos actúa. Pues es el phrónimos quien (de forma irritantemente circular) entiende bien y actúa bien. Dicho en términos de Heidegger: el phrónimos, retomando el hilo de la conversación (en que consistimos o en la que estamos) cuando hay que tomarlo y como hay que tomarlo, acierta con el "ahí" (con el cómo, con el cuándo y con el qué), en el acertar con el cual consiste el hacerse presente en su excelencia y verdad aquello de que se trata. En todo caso es en estos términos como 
Gadamer introduce esa su chocante idea de una «rehabilitación del prejuicio y de la autoridad" ${ }^{21}$.

\section{La idea de pragmática formal. Humboldt y Habermas}

Y es precisamente ese mismo Geschehen, es esa misma relación entre érgon y enérgeia, la que Habermas por su parte interpreta como reproducción del «mundo de la vida" (es decir, de la cultura, la sociedad y la personalidad) mediante la "acción comunicativa", haciendo recaer el "prejuicio" y la "autoridad" últimos precisamente sobre las estructuras formales de la razón ilustrada moderna.

Pues Habermas pone las pre-suposiciones formales universales del habla racional (en definitiva, pre-juicio racional y autoridad racional, como veremos) donde Gadamer pone el pre-juicio y la autoridad de la tradición. Pero lo hace, haciendo a la vez suyas la idea de Gadamer de «el diálogo que somos" y la idea de Gadamer de «una razón y un saber no desgajados del ser que ha devenido, del ser histórico". Las diferencias de lenguaje entre Gadamer y Habermas no deberían llevarnos a engaño acerca de los amplios solapamientos de los planteamientos de ambos, o por lo menos acerca de que, como he dicho, es principalmente discutiendo con Gadamer y contra él como Habermas proyecta su idea de pragmática universal del lenguaje, o como la recibe de K.-O. Apel, otro discípulo de Gadamer. En todo caso, lo que en la tercera parte de Verdad y método se entiende por "lingüisticidad como determinación básica del objeto hermenéutico" desempeña un papel igual de fundamental en Habermas, y Habermas recibe de Verdad y método ese concepto e incluso acaba radicadizándolo.

Por «acción comunicativa» entiende Habermas la acción coordinada por un "empleo del lenguaje orientado a entenderse». De ese empleo del lenguaje depende cualquier otro tipo de empleo del lenguaje. Es decir, el empleo del lenguaje orientado a entenderse viene supuesto, al menos como trasfondo, en cualquier otra forma de empleo del lenguaje, pues los supuestos más básicos de mundo dependen de él (enseguida explicaré esto). Por tanto, correlativamente, cualquier otra forma de acción depende o tiene a su vez como reverso o trasfondo, la acción comunicativa $^{22}$.

21 Ibíd., pp. 281 s.

${ }^{22}$ Cfr. J. Habermas, Teoría de la acción comunicativa, trad. M. Jiménez Redondo, 2 vols., Madrid, 1987. 
Veamos muy sucintamente qué es lo que quiere decir Habermas con esto, o cómo desmenuza Habermas esa idea. Lo que Habermas quiere decir con tal "orientación a entenderse" lo podemos explicar más o menos de la siguiente forma. Al hacer un acto de habla, no puedo menos de pretender, dice Habermas, que lo que digo se entiende (inteligibilidad), que lo que digo (si lo que hago es un enunciado) o los supuestos de existencia que lo que digo (si mi acción de hablar no consiste en enunciar) se cumplen (verdad), que mi acción de hablar se atiene al marco normativo que en esa acción se supone (rectitud), y que lo que digo se ajusta a lo que pienso, es decir, que al hablar no estoy precisamente ocultando aquello que quiero hacer (veracidad).

O a su vez, lo que digo puede cuestionarse desde cuatro puntos de vista. Digo por ejemplo: it rains, y alguien replica: no entiendo, yo no sé inglés; o alguien dice: eso no es verdad, hace un día espléndido; o alguien dice: ¿por qué molesta usted hablando del tiempo en una circunstancia como la presente?, cállese, por favor; o alguien dice: ‘a dónde querrá llegar éste hablándonos ahora del tiempo, en lugar de entrar en tema? Esas cuatro pretensiones de validez distintas (inteligibilidad, verdad, rectitud, veracidad) representan, pues, cuatro dimensiones de lo que llamamos "razón", desde las que cualquier acto de habla resulta "susceptible de crítica», y se refieren al aspecto de validez de las cuatro relaciones que al hablar inexorablemente establecemos con el mundo. Con el mundo objetivo, pues al hablar nos entendemos sobre algo. Con el mundo social, pues al hablar nos entendemos con alguien. Con el propio mundo subjetivo, pues al hablar $m e$ entiendo con otros. Con el propio medio del entendimiento, pues al hablar nos entendemos. Hablar es así básicamente entenderse con alguien sobre algo.

Digo que hablar es básicamente un entenderse con alguien sobre algo. Veamos qué quiere decir Habermas con «básicamente».

Cuando lo que digo queda cuestionado en alguno de esos aspectos, la acción (la acción coordinada mediante ese mi decir) queda perturbada, y o bien la pretensión de validez puesta en cuestión (es decir, la correspondiente perturbación) es objeto de un arreglo sobre la marcha, o bien en caso de cuestionamientos pertinaces se produce una situación de violencia abierta o encubierta, o bien suspendiendo temporalmente la acción y "adoptando una actitud hiporética» se pasa a examinar las razones que asisten o dejan de asistir a la pretensión de validez que 
ha quedado en el aire; esta última posibilidad viene siempre también constitutivamente inscrita en el propio hablar.

Según las distintas pretensiones de validez, tendremos entonces distintos tipos de "discurso" o de «discusión»: discurso hermenéutico (inteligibilidad), discurso teórico (verdad), discurso práctico (rectitud), crítica psicoanalítica o crítica ideológica (veracidad). Naturalmente, no puedo entrar aquí en una caracterización de los distintos tipos de discurso; me voy a limitar a hacer un par de observaciones.

Obsérvese en primer lugar el lugar tan reducido, el campo tan restringido y limitado que en este mapa de la razón le queda a la hermenéutica. La "pretensión de universalidad de la hermenéutica» casi se queda en nada. Y puede que, correlativamente, también se nos quede en nada su ontologización por Gadamer; pero esto hemos de verlo aún.

Obsérvese en segundo lugar, y en otro orden de cosas, que si hablar implica inexorablemente pretender validez para lo que se dice, ello implica que el hablar queda perennemente en vilo. Pues toda pretensión de validez que el hablante entabla, el oyente puede admitirla, pero también cuestionarla, pues entender (como hemos visto) es posicionarse con razones (al menos potencialmente) respecto a dicha pretensión. Ahora bien, el cuestionamiento, por su propia naturaleza, pone siempre también en perspectiva, como una posibilidad que le es constitutiva, la posibilidad de un acuerdo "discursivo", de un acuerdo con razones, de un acuerdo fundado. Por tanto, en cuanto abrimos la boca, nos queda puesta en perspectiva (por así decir) la posibilidad de principio de un acuerdo racional, sólo sobre cuyo reverso la violencia y la sinrazón se nos revelan en ese su carácter de violencia o sinrazón.

Pues bien, como perspectiva normativa estructuradora del discurso teórico (al que la acción comunicativa remite como a una "forma de reflexión" suya) Habermas apela a aquella noción de teoría verdadera de Ch. S. Peirce, conforme a la que «verdadera es la teoría que está llamada a que en ella se pongan de acuerdo todos los que investigan", entendiéndose por "todos los que investigan" una comunidad indefinida de investigación y comunicación ${ }^{23}$. Si por «realidad»

${ }^{23}$ Ch. S. PeIRCE, "How to make our ideas clear», en Ch. S. Peirce, Selected Writings, ed. Philip P. Wiener, Nueva York, 1966, p. 133. 
entendemos el correlato de un enunciado verdadero o de enunciados verdaderos, entonces resulta que para nosotros no hay realidad, no hay mundo, sino a través de la comunicación. Por eso, el empleo del lenguaje orientado a entenderse es el más básico de todos y se presupone en todas las demás formas de empleo del lenguaje, y por eso también hablar es básicamente un entenderse con alguien sobre algo.

Pero el hombre sabe de la justicia e injusticia también porque es un animal que habla, como decía Aristóteles al principio de su Política ${ }^{24}$. Y así, como perspectiva normativa estructuradora del "discurso práctico" (al que la acción comunicativa remite asimismo como "forma de reflexión» suya) Habermas introduce el llamado "principio de discurso ${ }^{25}$ (del que en la construcción de Habermas resultarán el "principio moral" y el "principio democráticon) conforme al que «una norma es legítima si y sólo si a ella hubieran podido prestarle su asentimiento todos los posibles afectados por ella como participantes en discursos racionales", entendiéndose por "discursos racionales» los estructurados de forma tal que las decisiones tomadas en ellos tengan a su favor la presunción de contar con los mejores argumentos. (No entro en la cuestión de las perspectivas normativas específicas de lo que Habermas llama «discurso hermenéutico» y «crítica ideológica").

Habermas propone, pues, desarrollar la idea de Humboldt de que hablar es básicamente «un entenderse con alguien sobre algo" en términos de una "pragmática universal" que habría de consistir en una reconstrucción de las suposiciones formales universales de todo entendimiento posible, o de los supuestos formales universales del empleo del lenguaje orientado a entenderse, que es el más básico de todos. Obsérvese que esas suposiciones contendrían los "prejuicios" y la "autoridad" contra los que pueden o podrían acabar quebrándose cualquier otro prejuicio y cualquiera otra autoridad, es decir, contendrían los "prejuicios" y "autoridad" de la razón, que en todo caso mantienen en vilo a todo prejuicio y autoridad materiales e históricos. Entre esas suposiciones básicas figura, como acabamos de ver, el "principio de discurso» que Habermas entiende como una reformulación del imperativo categórico de Kant.

${ }^{24}$ ARISTOTELES, Politica, 1253 a 7 ss.

${ }^{25}$ J. Habermas, Faktizität und Geltung, Fráncfort, 1992, pp. 138 s. 
Y frente a la «ontología hermenéutica» esta pragmática universal ni se entiende ni necesita entenderse a sí misma como ontología. Al contrario, comporta un rechazo de toda ontología, y se entiende a sí misma como una "transformación de la filosofía trascendental», por recordar una bien conocida expresión de K.-O. Apel. La tradición ontológica, transformada y desplazada por la moderna filosofía del sujeto, se tornaría aún más lejana y obsoleta ante este tipo de pragmática formal o pragmática trascendental. Ésta se entiende a sí misma como una crítica de la filosofía trascendental, inspirada por Wittgenstein y Gadamer, y efectuada en términos de pragmática del lenguaje. Y respecto a la tradición de filosofía analítica del lenguaje, esta pragmática formal o universal se entiende a sí misma como una crítica de la centralidad que en la filosofía analítica ocupaba la semántica filosófica en sustitución de las disciplinas básicas que en la tradición filosófica habían sido la teoría del conocimiento y antes la ontología.

No puedo entrar en los destinos de la idea de pragmática universal de Habermas, o de pragmática trascendental de K.-O. Apel. Pero creo que lo más sensato que se puede decir de ellas es que simplemente y definitivamente se quedaron en ideas o programas, que nunca llegaron a sustanciarse. Y ello pese a lo vigorosos que parecieron los rasgos con los que inicialmente se presentaron. Ninguno de esos rasgos sigue hoy en pie.

\section{De vuelta a Hegel y a Heidegger}

A mí en todo caso, las dudas respecto a ellas ( $y$ las dudas sobre la semántica filosófica como disciplina filosófica básica) me devolvieron a Aristóteles, a Kant, a Hegel y a Ser y tiempo ${ }^{26}$.

Como ya empieza a quedar definitivamente claro (con la publicación de los cursos de Heidegger), Ser y tiempo nace lentamente como un persistente comentario e inacabable interpretación de Aristóteles (y de una simultánea crítica de Hegel como culminación de la metafísica griega y de una revisión de Kant como

${ }^{26}$ Cfr. M. JimÉnEZ Redondo, "Heidegger sobre el principio moral de Kant», en: Ángel Martín Faerna y Mercedes Torrevejano (eds.), Identidad, individuo e historia, Valencia, 2003, pp. 161 ss. 
crítico de esa metafísica) y ello tras que las "consecuencias del idealismo alemán", tal como éstas se entendieron en la Fenomenología, devolvieran a los protagonistas de ésta a los griegos. En ese comentario e interpretación quedan en primer plano los conceptos de la filosofía práctica de Aristóteles, o en todo caso desempeñan un papel cada vez más central ${ }^{27}$.

La praxis como aquella forma de acción que no tiene su érgon fuera de sí sino para la que su érgon es ella misma, que Heidegger traduce por Dasein, es decir, la forma de ser como la que la existencia se encuentra siendo en su ser "suyamente" ella, tiene su exacto trasunto en el ser racional que se encuentra siendo en sí un fin, un fin en sí, del que deriva para Kant (o en el que radica para Kant) el imperativo categórico. La forma de excelencia del érgon en que la existencia se encuentra consistiendo consiste en un haberse ésta (en su no estar ya para otra cosa, en su encontrarse como siendo un télos en sí) de forma tal que ésta acierte consigo, en la que ésta dé en el centro de sí, en la que ésta llegue a tenerse propiamente o en el modo de la propiedad.

Para la "existencia oceánica» (Schmitt), o para la condición humana moderna, o para el narciso moderno, que sólo da consigo mirándose en las aguas del abismo en que consiste, es decir, proyectándose sobre la posibilidad más radical de todas, aquella que radicalmente le individúa, la de también-poder-no-ser, para esa existencia, digo, el tenerse con propiedad a sí como el fin en sí como el que se encuentra siendo, sólo puede consistir en proyectarse sobre esa posibilidad que radicalmente le individúa a la vez que destruye toda pretensión de distinción o superioridad, la posibilidad digo de también no ser.

Y en ello radica lo más básico de la tradición que la existencia se hace de sí misma a sí misma, la cual consiste en un venir a lo que yo ya siempre era y que insustituiblemente me individúa, es decir, la posibilidad de ser nada, la posibilidad más extrema de mí (péras) que circunscribe (hóros) aquello como lo que últimamente me encuentro siendo (ousía). Lo que Heidegger describe como temporalidad original (un venir a lo que ya siempre se era siendo así presente) no son sino las "ekstáseis" de la ousia aristotélica, referidas a aquello en que la existencia humana moderna se encuentra consistiendo.

${ }^{27}$ Cfr. M. Heidegger, Phänomenologische Interpretationen zu Aristoteles (1922), Reclam, Stuttgart, 2003. 
A este cómo de la existencia en el serse ella lo que ella ya siempre era (y ya para Aristóteles la areté es un cómo, en ello muy particularmente insiste Heidegger) apunta asimismo la formalidad del imperativo categórico de Kant. De modo que al cabo, según Heidegger, no habría diferencia de estructura entre la praxis aristotélica y aquella imperativa formalidad de la razón práctica de Kant, a la que la existencia se llama a sí misma, conforme a la que «no debes dejarte tratar nunca sólo como un medio; sé siempre también el irreferencial fin en sí como el que te encuentras siendo ${ }^{28}$. También contra la radical experiencia de la finitud, de la que derivarían las estructuras de la conciencia moderna en la formalidad que ofrecen, se quiebran en definitiva todo prejuicio y toda autoridad materiales.

Naturalmente, no puedo entrar en esta temática. Pero lo que estoy tratando de señalar con estas observaciones un tanto dispersas sobre razón práctica es que la antiilustrada "rehabilitación del prejuicio y de la autoridad" que Habermas achaca en Gadamer a una ontologización de la hermenéutica, se debe más bien a una combinación de dos cosas: a una ontologización insuficiente (en la que Gadamer abandona casi todo el análisis que en la segunda parte de Ser y tiempo se hace de la finitud de la existencia, de modo que toda la discusión ontológica de Heidegger se viene a reducir a las categorías de interpretación e historicidad) y junto con ello a una centralidad de la lingüisticidad, que, tal como Gadamer la toma de Humboldt, es ajena a Ser y tiempo. Y me parece que estos achaques de la obra de Gadamer difícilmente podían remediarse con proyectos de pragmática formal que casi comparten o compartían con Gadamer sus mismos vicios (el de operar con nociones ontológicas no aclaradas y el de centrarse en la categoría de lingüisticidad) ${ }^{29}$.

${ }^{28}$ Cfr. I. KANT, Metaphysik der Sitten (Rechtslehre), en: Immanuel Kant Werke VIII (ed. Weischedel), Suhrkamp, Fráncfort, 1956, p. 344.

${ }^{29}$ Cfr. J. HABERMAS et alii, "El ser que puede ser comprendido es lenguaje»: homenaje a HansGeorg Gadamer, Síntesis, Madrid, 2001. 